\title{
Estudo de documentos curriculares prescritos: (de)compondo uma metodologia de investigação
}

\section{Study of prescribed curricular documents: (de)composing an investigation methodology}

\author{
Fabiany de Cássia Tavares Silva* \\ Christiane Caetano Martins Fernandes*
}

\begin{abstract}
RESUMO
Este texto expõe os procedimentos metodológicos utilizados em um Programa de Pesquisa que realiza análises sobre documentos curriculares prescritos, também conhecidos como parâmetros, orientações, diretrizes, referenciais, programas e/ou planos, produzidos por redes de ensino estaduais e/ou municipais. Os procedimentos são baseados em uma versão do método de comparação intitulada "estudos comparados", que suporta outra representação ou outro design qualitativo de comparação, cruzando as áreas de educação comparada, história da educação e sociologia. As fontes de investigação selecionadas são dissertações e teses. De um lado, por constituir expressão de poder simbólico, de dados de enunciação, de fazer ver e crer, de confirmar ou de transformar os conteúdos do 'mundo curricular'. De outro, por disponibilizar um 'conhecimento poderoso', validado pela crença da/na legitimidade das escolhas e de quem as legitima, crença cuja produção torna relevante os estudos acadêmicos sobre documentos curriculares prescritos. E, por fim, porque a produção de análises sobre documentos curriculares e a produção de dissertações e teses são algumas das ações do Programa.
\end{abstract}

Palavras-chave: Método. Estudo Comparado. Documentos Curriculares Locais. Currículo. Dissertações e Teses.

* Universidade Federal do Mato Grosso do Sul. Faculdade de Educação. Campo Grande, Mato Grosso do Sul, Brasil. E-mail: fabiany@uol.com.br. http://orcid.org/0000-0002-7106-690X. E-mail: christianecmfernandes@gmail.com. https://orcid.org/0000-0002-3501-853X. 


\begin{abstract}
This text exposes the methodology procedures adopted by a Research Program that analyzes prescribed curricular documents, also known as parameters, orientations, guidelines, references, programs and/or plans, produced by state and/or municipal education systems. The procedures are based on a version of the comparison method entitled comparative studies, which supports another representation, or another qualitative comparison design, by crossing the areas of comparative education, education history and sociology. The sources of investigation selected are dissertations and thesis. On the one hand, as they establish an expression of symbolic power, enunciation data, making see and believe, and confirming or changing the contents of the 'curricular world'. On the other hand, as they provide a 'powerful knowledge', validated by the belief in the legitimacy of the choices and of the people who legitimize them, a belief whose production values academic studies on prescribed curricular documents. And, lastly, because reviewing curricular documents and writing dissertations and thesis are some of the actions developed by the members of the Program.
\end{abstract}

Keywords: Method. Comparative Study. Local Curricular Documents. Curriculum. Dissertations and Theses.

\title{
Introdução
}

Este texto expõe os procedimentos metodológicos utilizados em um Programa de Pesquisa que realiza análises sobre documentos curriculares prescritos, também conhecidos como parâmetros, orientações, diretrizes, referenciais, programas e/ou planos, produzidos por redes de ensino estaduais e/ou municipais. Os procedimentos são fundados em uma versão do método da comparação, intitulada estudos comparados, desenvolvida nas orientações de dissertações, teses e pesquisa do/pelo Observatório de Cultura Escolar, grupo de estudos e pesquisas cadastrado no Conselho Nacional de Desenvolvimento Científico e Tecnológico (CNPq) e sediado no Programa de Pós-Graduação em Educação da Universidade Federal de Mato Grosso do Sul.

Defendemos os documentos curriculares prescritos como objetos de pesquisa, desconstruindo certa configuração discursiva acerca da sua irrelevância, porque os apreendemos como portadores de "um conteúdo prefigurado, previsto e controlado por uma força externa preexistente" (WILLIAMS, 2010, p. 45). A par disso, os documentos curriculares assumem papel de destaque nas relações educativas, sobretudo por orientar-se pelos determinantes constantes 
dos documentos curriculares nacionais, delineados pelo seu reconhecimento na construção histórica do acesso aos conhecimentos científicos, fundamentados na organização de um percurso formativo, ou melhor, documentos de identidades que inserem concepções de sujeito, de cidadão, de sociedade e de escolarização, entre outras.

Esses documentos também são apreendidos como um campo de disputa pela hegemonia ${ }^{1}$ e como um espaço de luta e de contradição. Contudo, a depender das forças pelas quais se constitui, esse campo configura-se como organizador de um sistema de distribuição de conhecimento para cumprir determinadas finalidades sociais. Acresce-se a essa apreensão o 'lugar' que tais documentos ocupam no espaço dos estudos curriculares, porque se diferenciam de outros tipos de materiais, ao serem desenhados e propostos para o comprimento de funções determinadas pela difusão e pelo desenvolvimento prático dos processos de ensinoaprendizagem ${ }^{2}$ em um determinado projeto curricular de uma, também determinada, rede de ensino.

Assim, estamos orientados por um questionamento central: como esses documentos se transformam em fontes de estudos na produção acadêmica, particularmente em dissertações e teses? Para tentar responder a essa questão, investigamos 13 dissertações e duas teses de doutoramento, selecionadas na Biblioteca Digital de Dissertações e Teses (BDTD) e identificadas pelos descritores currículo, escola básica, educação básica, distribuição de conhecimentos, conhecimento (como construções intelectuais historicamente produzidas pela humanidade) e redes de ensino.

A escolha por dissertações e teses para tal análise prende-se, também, ao exercício de escrita de dissertações e teses, desenvolvido por este Programa de Pesquisa. Essa produção, de alguma maneira, é revisitada quando objetivamos análises sobre as reuniões e análise e interpretação de temas, evidenciando o conhecimento de literatura existente sobre o assunto e a capacidade de sistematização dos dados. Os documentos curriculares prescritos analisados em dissertações e teses respondem/resultam de um recorte temporal, orientado pela implantação e análise dos Parâmetros Curriculares Nacionais (PCN) para

1 Gramsci (1982) conceitua hegemonia como um conjunto de práticas, expectativas, significados e valores que, quando experimentados como prática, parecem confirmar-se reciprocamente, constituindo um sentido de realidade para a maior parte dos membros de uma sociedade. E, ainda, carrega um sentido de ser absoluta, porque é experimentada como uma realidade de que a maior parte das pessoas dificilmente conseguirá ir além. Contudo, não se trata de um sistema estático, posto que depende de um processo social de incorporação, em que a significação econômica é de fundamental importância na sociedade atual.

2 Utilizamos essa grafia para expressar compreensão acerca da indissociabilidade entre ensino e aprendizagem. 
o Ensino Fundamental, Referenciais Curriculares Nacionais para a Educação Infantil (RCNEI), Diretrizes Curriculares Nacionais Gerais para a Educação Básica (Resolução CNE/CEB n ${ }^{\circ}$ 4, de 2010) e as Diretrizes Curriculares Nacionais para a Educação Infantil (Resolução CNE/CEB n ${ }^{\circ} 5$, de 2009). Esses documentos são tomados como espaços e tempos de projeções da (re)invenção dos princípios de uma escola justa, entendida como objeto de um novo contrato educativo (sociedade e governo), que assume formas de incluir 'a todos': "A escolaridade envolve o fornecimento de acesso ao conhecimento especializado [poderoso] incluído em diferentes domínios" (YOUNG, 2007, p. 1295). A defesa de Young na discussão de 'conhecimentos poderosos' está assentada na emergência da distribuição de conhecimentos científicos, especialmente aos menos favorecidos, visto que encontram na escola um dos poucos - ou talvez o único - espaços no qual têm o direito de acessá-los.

\section{(De)compondo os Estudos Comparados: ferramenta metodológica de Programa de Pesquisa}

O diálogo com as humanidades, particularmente a educação, a história da educação e as ciências sociais, tem tornado ineficiente a proposição de qualquer estudo comparado que desconsidere, na explicação de qualquer fato ou fenômeno histórico, social e educativo, as relações com as convicções políticas, econômicas e/ou filosóficas da sociedade. Da mesma forma, as mudanças educacionais não podem ser comparadas sem um mínimo de análise sobre o sentido histórico do período em que são construídas/propostas.

Assim, temos constituído práticas de pesquisa alimentadas por procedimentos metodológicos que entendemos como uma versão particular dos estudos comparados. Essa versão recorre à educação comparada, tomando-a como resultado de um movimento duplo; de um lado, marcado por uma presença crescente das questões educativas na criação de identidades escolares, definidas não tanto sob uma perspectiva geográfica, mas no sentido de uma pertença a certas comunidades discursivas. De outro, deslocando-se da referência tradicional interpaíses para dimensões simultaneamente intranacionais e extranacionais, isto é, centradas nas comunidades de referência dos agentes locais e nos processos de regulação em níveis nacional e internacional (SILVA, 2016).

Advogamos uma perspectiva estrutural nacional e local das causas e processos, não recorrendo às referências sistemáticas da comparação, isto é, às reconhecidas estruturas internacionais/estrangeiras e à evolução histórica 
mundial. Concebemos os estados e municípios como organizações administrativas e coercivas, potencialmente relativizadas em relação aos interesses e às estruturas socioeconômicas.

Acrescemos, a essa movimentação, a 'reinstituição' de um contexto sociopolítico tomado sob a perspectiva de uma história social comparada, investigada pelos referentes do método histórico, que tem nos permitido buscar as diferenças e semelhanças do/no particular, a partir dos processos políticos mais amplos (compreender a política como processo) e reconstruí-las como parte de uma determinada realidade sempre complexa, aberta às transformações, sob a ação dos sujeitos sociais (utilizando a história-social como método).

Dessa forma, aproximamo-nos do processo de apreensão das dinâmicas, das transições, das relações sócio-culturais-econômicas, como diferentes textos que levam à compreensão dos discursos, que alimentam situações de dependência e lógicas de discriminação, que constroem maneiras de pensar e de agir. Trata-se de um exercício mais próximo das Ciências Sociais comparadas, vinculadas a uma espécie de Sociologia Histórica, apontada por Pereyra (1990) como um dos instrumentos promissores na construção de conhecimento crítico acerca da realidade educacional.

Também é possível considerar que as Ciências Sociais e da Educação não são vistas

[...] como meros projetos nacionais, mas como uma globalização no planejamento da sociedade e do povo por intermédio da ciência. As narrativas e as imagens diziam respeito ao cosmopolitismo, isto é, a uma individualidade guiada pela razão e pela ciência na realização da ação humana e do progresso social, tido como universalista em seus objetivos, ainda que tais objetivos fossem historicamente específicos. (POPKEWITZ, 2012, p. 475).

A nova epistemologia do conhecimento, de cunho sócio-histórico, define perspectivas de pesquisa centradas não apenas na materialidade dos fatos educativos, mas também nos mercados simbólicos que os descrevem, interpretam e localizam em um dado espaço-tempo (POPKEWITZ, 1998).

Trata-se de mercado habitado por grupos que produzem e/ou fazem circular discursos, que podem ou não implicar uma política de não isenção na escrita da história, o que, para Fendler (2013), significa que estão dadas 
[...] a oportunidade e a obrigação de questionar todas as variáveis como potenciais candidatos para análise historiográfica minuciosa. Afinal, como podemos isentar de nossas investigações históricas as ferramentas de pesquisa histórica e das linguagens que utilizamos para escrever a história? Todos os nossos cuidados metodológicos, processos de avaliação, classificações analíticas e tradições narrativas são infestadas por, vinculadas a, e (até certo ponto) dependentes, implacavelmente, das flutuantes contingências históricas de tempo, espaço e poder. (FENDLER, 2013, p. 228 , tradução nossa). ${ }^{3}$

A realidade curricular em comparação leva-nos à descoberta de regularidades, percepção de deslocamentos e transformações, construção de modelos e tipologias, identificação de continuidades e descontinuidades, semelhanças e diferenças, explicitando determinações mais gerais, que regem os fenômenos sociais. Contudo, tais descobertas também são apenas relativamente precisas e sujeitas a um discurso intenso e complexo, que traz à tona os pontos de vista contrastantes, que caracterizam os vários agentes educacionais.

Para compreendermos esses discursos, damos forma às áreas de comparação como expressão dos conceitos de campo e habitus, propostos por Bourdieu. Os campos, na concepção bourdieusiana, são espaços de relações objetivas que possuem uma lógica própria. Bourdieu (2008, p. 50) afirma ser o campo tanto um campo de forças, "cuja necessidade se impõe aos agentes que nele se encontram envolvidos", quanto um campo de lutas, "no interior do qual os agentes se enfrentam, com meios e fins diferenciados conforme sua posição na estrutura do campo de forças, contribuindo assim para a conservação ou a transformação de sua estrutura".

As áreas de comparação, quando eleitas, são compreendidas na inter-relação entre os campos educativo, social, simbólico e cultural. Assim, encontram-se inseridas em um espaço relacional, permeado por lutas de conservação e transformação das suas estruturas. São encaradas como estratégias e táticas e não apenas como expressão da repetição de um discurso simplesmente reproduzido, mas como um conjunto de disposições que vem sendo recriado, atualizado e, portanto, continuamente re-produzido (produzido de novo) no decorrer dos estudos sobre documentos curriculares.

3 “[...] an opportunity and obligation to question all variables as potential candidates for historiographical scrutiny. After all, how can we exempt from our historical investigations the very historical research tools and languages we use to write history? All of our methodological safeguards, processes of evaluation, analytical classifications, and narrative traditions are haunted by, tied to, and (to some extent) dependent upon, relentlessly fluctuating historical contingencies of time, space, and power" (FENDLER, 2013, p. 228). 
O conceito de campo está intrinsecamente ligado ao de habitus, definido como

[...] sistemas de disposições duráveis, estruturas estruturadas predispostas a funcionar como estruturas estruturantes, isto é, como princípio gerador e estruturador das práticas e das representações que podem ser objetivamente "reguladas" e "regulares" sem ser o produto da obediência a regras, objetivamente adaptadas a seu fim sem supor a intenção consciente dos fins e o domínio expresso das operações necessárias para atingi-los e coletivamente orquestradas, sem ser o produto da ação organizadora de um regente (BOURDIEU, 1983, p. 61, grifos no original).

O habitus mostra-se como uma ferramenta teórica capaz de responder a questão central colocada em relação às áreas de comparação, isto é, disposições estruturadas e estruturantes, que atuam como matrizes de percepção e ação continuamente recriadas no decorrer das análises. Dessa forma, constituindo doxas (um ponto de vista particular, o ponto de vista dos dominantes, que se apresenta e se impõe como ponto de vista universal) e nomos (avalia, rege e regula o que se faz), que orientam as análises curriculares. Ou seja, as áreas de comparação são entendidas como um habitus, incorporado pelos agentes do campo em questão, que orienta as estratégias nas relações de força desse campo.

As áreas de comparação, então, passam a ser tomadas como parte da caracterização de um universo discursivo. De um lado, representam a posição diferençada dos agentes segundo uma distribuição desigual de recursos materiais e simbólicos; de outro, um conjunto de esquemas simbólicos que tomam a forma de disposições ou modos potenciais socialmente adquiridos e tacitamente ativados de interpretar, classificar e avaliar.

\section{Estudo comparado de dissertações e teses para análise de documentos curriculares prescritos}

Utilizamos o estudo comparado no exercício de construção de dados sobre análises efetuadas em dissertações e teses na investigação de documentos curriculares prescritos, construídos/publicados por redes de ensino para a educação básica, nas etapas da Educação Infantil e do Ensino Fundamental. Nesse exercício, tomamos as dissertações e teses como objetos que informam sobre 
os estudos curriculares. Por isso, não exercitamos críticas sobre a qualidade das análises, tampouco negamos a relevância que os discursos construídos possuem. Compreendemos os diálogos como produtos científicos, como atos políticos, pelo fortalecimento que significam para o campo da pesquisa em/com currículo.

Para a escolha, realizamos levantamento na Biblioteca Digital de Teses e Dissertações (BDTD), tendo como critérios de inclusão e exclusão: identificação apenas dos trabalhos que objetivamente estudam documentos curriculares (propostas, referenciais, orientações e/ou diretrizes curriculares) produzidos por redes de ensino, no período de 2002 a 2012; o descarte dos trabalhos que investigam "o ensino de", "formação de professores", "saberes docentes" e produções a partir de "tratamentos de conteúdos de componentes curriculares específicos disponibilizados nos documentos curriculares".

De posse desses critérios, operamos com a seleção a partir dos descritores currículo, escola básica, educação básica, distribuição de conhecimentos, conhecimento (como construções intelectuais historicamente produzidas pela humanidade) e redes de ensino. Como resultado, totalizamos 13 dissertações e duas teses, a saber:

\section{QUADRO 1- DISSERTAÇÕES E TESES}

\begin{tabular}{|l|l|c|c|}
\hline \multicolumn{1}{|c|}{ TíTULOS } & AUTORIA/ANO & TITULAÇÃO & IES \\
\hline $\begin{array}{l}\text { Diretrizes curriculares do município de } \\
\text { Goiânia no contexto de uma política } \\
\text { curricular nacional }\end{array}$ & $\begin{array}{l}\text { Neisi Maria da Guia } \\
\text { Silva/2009 }\end{array}$ & Mestrado & UFG \\
\hline $\begin{array}{l}\text { A proposta curricular do estado de São } \\
\text { Paulo e os impactos das inovações no } \\
\text { projeto político e pedagógico da escola }\end{array}$ & $\begin{array}{l}\text { José Mauro M. } \\
\text { Fernandes/2010 }\end{array}$ & Mestrado & PUC/SP \\
\hline $\begin{array}{l}\text { A avaliação do currículo na rede } \\
\text { municipal de ensino: um estudo } \\
\text { multicaso e propositivo no contexto } \\
\text { institucional de escolas do ensino básico } \\
\text { de Salvador-Bahia }\end{array}$ & $\begin{array}{l}\text { Maria de Lourdes O. } \\
\text { Reis da Silva/2009 }\end{array}$ & Doutorado & UFBA \\
\hline $\begin{array}{l}\text { Ensino fundamental de nove anos: } \\
\text { repercussões da lei n 11.274/2006 na } \\
\text { proposta curricular da rede municipal de } \\
\text { ensino de Juiz de Fora }\end{array}$ & $\begin{array}{l}\text { Lilian Aparecida } \\
\text { Lima/2011 }\end{array}$ & Mestrado & UFJF \\
\hline $\begin{array}{l}\text { O que e como ensinar: proposta } \\
\text { curricular, materiais didáticos e prática } \\
\text { de ensino nas escolas públicas estaduais } \\
\text { em São Paulo (2008-2009) }\end{array}$ & $\begin{array}{l}\text { Thiago Figueira } \\
\text { Boim/2010 }\end{array}$ & Mestrado & PUC/SP \\
\hline $\begin{array}{l}\text { Proposta curricular para educação } \\
\text { infantil: (re)significando saberes docentes }\end{array}$ & $\begin{array}{l}\text { Elaine Luciana da } \\
\text { Silva Sobral/2008 }\end{array}$ & Mestrado & UFRN \\
\hline
\end{tabular}

(Continua) 
(Conclusão)

\begin{tabular}{|l|l|c|c|}
\hline $\begin{array}{l}\text { Educação infantil em Piraquara: entre as } \\
\text { idéias e as propostas pedagógicas (1993- } \\
2004)\end{array}$ & $\begin{array}{l}\text { Danielle } \\
\text { Marafon/2007 }\end{array}$ & Pestrado & PUC/PR \\
\hline $\begin{array}{l}\text { A construção do currículo do } 1^{\circ} \text { ano do } \\
\text { ensino fundamental de nove anos na rede } \\
\text { municipal de Balneário Camboriú }\end{array}$ & $\begin{array}{l}\text { Eliane de Fátima } \\
\text { Inglez Sinhori/2011 }\end{array}$ & Mestrado & UNIVALI \\
\hline $\begin{array}{l}\text { As orientações pedagógicas da educação } \\
\text { infantil em municípios de Santa Catarina }\end{array}$ & $\begin{array}{l}\text { Verena } \\
\text { Wiggers/2007 }\end{array}$ & Doutorado & PUC/SP \\
\hline $\begin{array}{l}\text { Referencial curricular nacional para } \\
\text { educação infantil: uma proposta } \\
\text { integradora ou interdisciplinar }\end{array}$ & Ariene Lopes/2011 & Mestrado & UNIVALI \\
\hline $\begin{array}{l}\text { O sistema nacional de avaliação básica: } \\
\text { vínculos entre avaliação e currículo }\end{array}$ & $\begin{array}{l}\text { Débora Raquel Alves } \\
\text { Barreiros/2003 }\end{array}$ & Mestrado & UERJ \\
\hline $\begin{array}{l}\text { Autonomia da criança: transição } \\
\text { da educação infantil para o ensino } \\
\text { fundamental, conforme as prescrições } \\
\text { oficiais }\end{array}$ & $\begin{array}{l}\text { Kelly Cristina dos } \\
\text { Santos/2007 }\end{array}$ & Mestrado & PUC/SP \\
\hline $\begin{array}{l}\text { Currículo de educação popular para } \\
\text { a educação infantil: limites, tensões e } \\
\text { possibilidades a partir da experiência do } \\
\text { município de Chapecó/SC }\end{array}$ & $\begin{array}{l}\text { Isabel Spingolon } \\
\text { Azambuja/2008 }\end{array}$ & Mestrado & UFSC \\
\hline $\begin{array}{l}\text { O currículo e a educação inclusiva: a } \\
\text { prática curricular e suas implicações } \\
\text { na inclusão escolar de alunos com } \\
\text { necessidades educacionais especiais }\end{array}$ & $\begin{array}{l}\text { Glaucia de Carmo } \\
\text { Xavier/2008 }\end{array}$ & Mestrado & PUC/MG \\
\hline $\begin{array}{l}\text { Inclusão escolar na Pré-Escola: o acesso } \\
\text { ao currículo }\end{array}$ & $\begin{array}{l}\text { Renata Almeida } \\
\text { Antunes/2008 }\end{array}$ & Mestrado & USP \\
\hline
\end{tabular}

FONTE: Elaborado pelas autoras

Além da tarefa de identificação, os descritores colaboram para apreender as leituras produzidas, a fim de identificar as contribuições, as considerações dos autores, as continuidades e descontinuidades e as semelhanças e diferenças que explicitam determinações mais gerais, que regem os fenômenos analisados.

$\mathrm{Na}$ tentativa de aprofundar a compreensão das questões que emergiram a partir da primeira leitura dos resumos, optamos por contabilizar o uso/a defesa de conceitos, noções ou ideias, com o propósito de nos aproximarmos das análises construídas com os documentos curriculares. A par disso, identificamos o que chamamos de áreas de comparação, particularmente, delineadas a partir de um procedimento de categorização e do exame das informações disponíveis na/para a identificação dos conteúdos das discussões curriculares. Dessa forma, elegemos as áreas organização curricular (política curricular), conhecimento (que é disponibilizado) e avaliação. 
Nessa eleição, agregamos conceitos para cada uma das áreas, de forma a localizar nossa leitura sobre versus as leituras produzidas pelos autores, ao tratar delas. Assim, abordamos a organização curricular como tradução da política curricular, próxima de análises que expõem, ou tentam expor, as disputas de interesses, os conflitos, as rupturas e as ambiguidades que, depois das reformas políticas de 1990, se encontram determinados pelo neoliberalismo. Essa doutrina dá forma ao projeto de reforma ideológica de nossas sociedades, da construção e da difusão de um novo senso comum, que fornece coerência, sentido e uma pretensa legitimidade às propostas de reforma econômica e educativa.

Controle, competitividade, liberdade de escolha dos consumidores, fixação do currículo com conteúdos básicos, assim como a submissão da educação às demandas do mercado de trabalho ou ao sucesso nos mercados abertos, foram as marcas das políticas educacionais das décadas de 1980 e 1990. Políticas que precisaram de outras linguagens, outros discursos para legitimar e se tornar mais apresentáveis e merecedoras de crédito, Políticas que deixaram um rastro que hoje contamina o que se entende por educação. (GIMENO SACRISTÁN, 2011, p. 19-20).

O conhecimento é compreendido na possibilidade de colocar em evidência a questão epistemológica, não sob a perspectiva de discutir o que deve ou não ser ensinado, mas aquilo que se apresenta como conhecimento nos documentos e o que se propõe como distribuição.

[...] o conhecimento, o saber e a ciência adquirem papel muito mais destacado do que anteriormente. Tornam-se cada vez mais evidentes que as transformações tecnológicas estão contribuindo para a constituição de uma sociedade marcada pela técnica, pela informação e pelo conhecimento. Desse modo, essa sociedade é caracterizada por um novo paradigma de produção e de desenvolvimento que tem como elemento básico a centralidade do conhecimento e da educação. (OLIVEIRA, 2009, p. 239).

A avaliação é uma figura atrelada às 'competências fundamentais', consideradas necessárias para a participação dos sujeitos nas sociedades democráticas. De uma forma sutil, mas incisiva, as competências se fortalecem, discursivamente, como essenciais para a concretização de princípios basilares da educação brasileira, da cidadania e da democracia. 
[...] possível constatar que as proposições oficiais se voltaram fortemente para a defesa de um projeto de formação posto por novos referenciais e um processo de avaliação que, articulados, poderiam elevar a qualidade de seus quadros e por decorrência elevar os indicadores positivos do processo de ensino-aprendizagem. (SILVA; ABREU, 2008, p. 529).

Esses conceitos são tornados áreas de comparação e evidenciados no debate do campo (no sentido bourdesiano) curricular, expressando um habitus revelador do poder simbólico dos currículos prescritos, qual seja, a prescrição como instrumento de dominação, cujos propósitos são desconhecidos, mas interessados nas práticas de ensino, de aprendizagem voltadas aos projetos de formação.

Contudo, registramos que, pelos limites aqui impostos, torna-se impossível expor os exercícios de rastreamento das/nas singularidades dos usos/das defesas das áreas de comparação em cada uma das dissertações e teses. Mesmo enfrentando a inexorabilidade dos procedimentos generalistas, entendemos que eles não inviabilizam a projeção da apreensão da complexidade do fenômeno analisado.

$\mathrm{Na}$ comparação dessas áreas, tanto as dissertações quanto as teses, por um lado, inserem análises de documentos curriculares publicados por/em municípios e estados brasileiros. Por outro, discutem a educação escolar como a principal referência do currículo, parte da atividade educativa, cujas atribuições convergem para a construção de 'identidades jurídicas', isto é, para sujeitos detentores de direitos e deveres do aprender pela distribuição de conhecimentos. Tais discussões cobrem diferentes áreas de interesse - tais como diferenças nos processos de ensinoaprendizagem, eficiência na organização escolar ou sistemas escolares - para as quais realizam análises de padrões ou relações entre diferentes variáveis.

As análises parecem não lidar com as intervenções específicas de um documento curricular para a melhoria da escolaridade ou a validade de diretivas políticas específicas. Em vez disso, tratam dos documentos como traduções de conhecimentos acessados, apreendidos como acionáveis, baseados em aproximações das decisões políticas e profissionais, orientadas para a/na construção de expertise em planejamento (definições de problemas e tarefas), ensino (escolhas ou estilos teóricos de compreensão das oportunidades e restrições) e avaliação (medições e números para reação). Acresce-se a isso que se constituem em pontos de contato entre o campo da teoria, o campo da política curricular e o mundo da escola, pensada para a Educação Infantil e o Ensino Fundamental, captando, ou tentando captar, parte das prescrições e "regulações" da oficialidade.

Contudo, a 'legitimidade' dos documentos curriculares como material de orientação da ação docente corrobora com a ideia de que 
[...] Os programas e planos de estudos [currículos] não são respeitados. Paradoxalmente, enquanto os professores têm o hábito de afirmar que são constrangidos pelos programas, as pesquisas mostram que eles não os seguem e que somente os conhecem de modo aproximado. [...] Sejam lá quais forem as razões, os programas não têm força de lei junto aos executores da educação e é em vão esperar que tais práticas serão mudadas pela promulgação de listas de objetivos, de competências ou mesmo pela publicação de um currículo estruturado. (CRAHAY, 2013, p. 38).

A par disso, também, incorrem na localização de um dos instrumentos de 'verificação' do alcance da justiça no processo de seleção e distribuição de conhecimentos num sistema educacional, apontados por Crahay (2000), isto é, as medidas de desempenho dos alunos obtidas por testes padronizados em larga escala.

Nesse caso, as dissertações e teses colocam os documentos curriculares na condição de portadores de informações sobre o contexto - e variáveis - em que a comparação somente incide sobre os resultados, construídos por um conjunto de variáveis pertencente/construído por/para cada lócus de pesquisa.

Apreendemos que, por meio das análises de Diretrizes, Propostas, Orientações, Referenciais e/ou Parâmetros curriculares, os pesquisadores de currículo (integrados às chamadas comunidades epistêmicas/acadêmicas) constroem diálogos com as redes de ensino, selecionando os conhecimentos que lhes interessam, prescrevendo formas de análise e sugerindo reorientações teóricas, metodológicas, mas tomando-os como influenciadores, ou promotores, de reformas educativas e instrucionais de cada administração/governo local.

Sobre essa condição dos documentos curriculares, encontramos, como 'conclusões de análise', uma familiaridade nos retratos informativos das redes de ensino sobre a escola e a função dos conhecimentos curriculares, combinados em análises multicamadas, em que as composições, tanto das escolas como da ação curricular, são levadas em consideração, bem como a força de associações entre diferentes variáveis. Reconhecemos isso, mas, pelos limites deste texto, não temos condições de identificar os mecanismos casuais que informam essas análises (o que faremos em outra publicação). 


\section{Notas finais}

A proposição deste texto orienta-se pela exposição dos procedimentos metodológicos utilizados em um Programa de Pesquisa fundados em uma versão do método da comparação intitulada estudos comparados, tornada uma ferramenta metodológica, não assentada apenas em uma pretensão de busca de diferenças e semelhanças entre os universos de análise, mas em microrrealidades educativas, sob a perspectiva de construir macroconclusões de estudos.

A construção de análises retrata dois movimentos que expõem a realidade curricular do/no campo educativo e o reconhecimento de seus processos histórico-sociais. No tocante à exposição da realidade, os documentos curriculares prescritos são analisados a partir de suas contradições e complexidades inerentes aos diferentes contextos políticos e partidários de produção, dos saberes das comunidades disciplinares das redes de ensino, mas orientados por informações de 'diagnósticos' fundamentados nas avaliações de larga escala. O segundo movimento é o reconhecimento dos processos histórico-sociais reveladores das intenções da formação escolar e dos determinantes econômicos, políticos, sociais que as alimentam, fundados em um ser biológico, cognitivo desconectado da cultura.

As dissertações e teses são uma espécie de fabricação de estudos acadêmicos, que se preocupam com documentos curriculares prescritos, mas constituídos por um sentido interpretativo para a forma como eles incrementam etapas e disciplinas acadêmicas da/na educação básica. Acresce-se, a isso, que os autores/produtores estabelecem, nos espaços da produção acadêmica, seus trabalhos como fontes de denúncia e resistência ao desiquilíbrio de forças entre os processos de seleção e distribuição de conhecimentos e os indivíduos que dele participam.

Dito de outro modo, as dissertações, as teses e os documentos curriculares prescritos analisados por elas constituem agentes poderosos de divulgação dos conteúdos, objetos e fontes dos estudos curriculares, propiciando o acesso aos recursos necessários para a configuração dos graus de racionalidade informados/ informantes dos processos de escolarização propostos por municípios e estados. Disponibilizam, ainda, o 'conhecimento poderoso', fruto das análises dos 'conhecimentos especializados' selecionados, distribuídos pelas/nas áreas de conhecimentos, validando uma análise respaldada pelos indícios das escolhas orientadas, no nível dos discursos, pelo enfrentamento da diferença, desigualdade e/ou diversidade próprias da realidade educacional brasileira. 
Essa imagem dos documentos curriculares locais prescritos, em estreita associação com as produções acadêmicas, não é nova, mas não se tornou relevante a ponto de materializar-se em estudos sobre as bases da identificação das características dos ambientes de ensino e aprendizagem, dos conhecimentos selecionados, e das distinções no seu uso na organização escolar e nos sistemas educativos.

Por fim, o exercício aqui proposto de (de)composição de uma metodologia de investigação no estudo de documentos curriculares prescritos acaba por registrar, além do desenvolvimento de uma pesquisa, um processo de condensação das principais problemáticas metodológicas com que se defronta a comparação desde o seu aparecimento, isto é, a combinação adequada e a dialética entre os elementos da estrutura e da ação humana, na pesquisa sobre currículos, e entre os elementos da singularidade e da universalidade dos processos educativos sociais. Combinação e dialética que problematizam as raízes metodológicas da comparação, que são indutoras da procura pelo 'outro', tido sempre como 'o estrangeiro', sobre o qual se estruturam os argumentos.

\section{REFERÊNCIAS}

BOURDIEU, P. O Poder Simbólico. Lisboa: Difel, 1983.

. Razões Práticas. São Paulo: Papirus, 2008.

BRASIL. Parâmetros curriculares nacionais: introdução aos parâmetros curriculares nacionais. Brasília: MEC, Secretaria de Ensino Fundamental, 1997a. 126p.

. Referencial Curricular Nacional para a Educação Infantil. Brasília: MEC/ Secretaria Ensino Fundamental, 1997b. 126p.

. Resolução $n^{\circ} 5$, de 17 de dezembro de 2009. Fixa as Diretrizes Curriculares Nacionais para a Educação Infantil. Conselho Nacional de Educação, Câmara Educação Básica. Diário Oficial da União, Brasília, 18 de dezembro de 2009, Seção 1, p. 18.

. Resolução $n^{\circ}$ 04, de 13 de julho de 2010. Diretrizes Curriculares Nacionais para

a Educação Básica. Conselho Nacional de Educação, Câmara Educação Básica. Diário Oficial da União, Brasília, 14 jul. 2010, Seção 1, p. 824.

CRAHAY, M. Como a escola pode ser mais justa e mais eficaz? Cadernos Cenpec, v. 3, n. 1, p. 9-40, jun. 2013.

. L'école peut-elle-être juste e efficace?De l'égalité des chances à l'égalité des acquis. Belgique: De Boeck Université, 2000. 
FENDLER, L. There Are No Independent Variables in History. In: POPKEWITZ, T. S. (Org.). Revisioning the History of Education Transnational Perspectives on its Questions, Methods, and Knowledge (p. 223-244). New York: Palgrave Macmillan, 2013.

GIMENO SACRISTÁN, J. Educar por Competências: o que há de novo? Porto Alegre: Artmed, 2011.

GRAMSCI, A. Cadernos do Cárcere. v. 3: Maquiavel. Notas sobre o Estado e a política. Rio de Janeiro: Civilização Brasileira, 1982.

OLIVEIRA, D. A. As políticas educacionais no governo Lula: rupturas e permanências. $R B P A E$, v. 25, n. 2, p. 197-209, maio/ago. 2009.

PEREYRA, M. A. Por otros usos de la comparación. Revista de Educación. Madrid, número extraordinário, p. 25-76, 1990.

POPKEWITZ, T. Struggling for the Soul - The Politics of Schooling and the Construction of the Teacher. New York \& London: Teachers College Press, 1998.

. O duplo significado de cosmopolitismo e os estudos comparados de educação. In: COWEN, R.; KAZAMIAS, A. M.; ULTERHALTER, E. Educação comparada: panorama internacional e perspectivas. Brasília: UNESCO, CAPES, 2012.

SILVA, M. R. da; ABREU, C. B. de M. Reformas para quê? As políticas educacionais nos anos de 1990, o "novo projeto de formação" e os resultados das avaliações nacionais. Perspectiva, v. 26, n. 2, 523-550, Florianópolis, jul./dez. 2008. p. 523-550.

SILVA, F. C. T. Estudos Comparados como método de pesquisa: a escrita de uma história curricular por documentos curriculares. Revista Brasileira de Educação, v. 21, n. 64, p. 209-224, jan.-mar. 2016.

WILLIAMS, R. Cultura e materialismo. São Paulo: Editora Unesp, 2010.

YOUNG, M. F. D. Pra que servem as escolas? Educação e Sociedade, Campinas, v. 28, n. 101, p. 1287-1302, set./dez. 2007. Disponível em: http://www.cedes.unicamp.br. Acesso em: 10 dez. 2017.

\section{Dissertações e teses}

ANTUNES, Renata Almeida. Inclusão escolar na Pré-Escola: o acesso ao currículo. 2008. Dissertação de Mestrado [Programa de Pós-Graduação em Educação], Universidade de São Paulo, 2008.

AZAMBUJA, Isabel Spingolon. Currículo de educação popular para a educação infantil: limites, tensões e possibilidades a partir da experiência do município de Chapecó/SC. 2008. Dissertação de Mestrado [Programa de Pós-Graduação em Educação], Universidade Federal de Santa Catarina, 2008. 
BARREIROS, Débora Raquel Alves. O sistema nacional de avaliação básica: vínculos entre avaliação e currículo. 2003. Dissertação de Mestrado [Programa de Pós-Graduação em Educação], Universidade Estadual do Rio de Janeiro, 2003.

BOIM, Thiago Figueira. O que e como ensinar: proposta curricular, materiais didáticos e prática de ensino nas escolas públicas estaduais em São Paulo (2008-2009). 2010. Dissertação de Mestrado [Programa de Estudos Pós-Graduados em Educação: História, Política Sociedade], Pontifícia Universidade Católica de São Paulo, 2010.

FERNANDES, José Mauro M. A proposta curricular do estado de São Paulo e os impactos das inovações no projeto político e pedagógico da escola. 2010. Dissertação de Mestrado [Programa de Estudos Pós-Graduados em Educação: Currículo], Pontifícia Universidade Católica de São Paulo, 2010.

LIMA, Lilian Aparecida. Ensino fundamental de nove anos: repercussões da lei n 11.274/2006 na proposta curricular da rede municipal de ensino de Juiz de Fora. 2011. Dissertação de Mestrado [Programa de Pós-Graduação em Educação], Universidade Federal de Juiz de Fora, 2011.

LOPES, Ariene. Referencial curricular nacional para educação infantil: uma proposta integradora ou interdisciplinar. 2011. Dissertação de Mestrado [Programa de Pós-Graduação em Educação], Universidade do Vale do Itajaí, 2011.

MARAFON, Danielle. Educação infantil em Piraquara: entre as idéias e as propostas pedagógicas (1993-2004). 2007. Dissertação de Mestrado [Programa de Pós-Graduação em Educação], Pontificia Universidade Católica do Paraná, 2007.

REIS DA SILVA, Maria de Lourdes O. A avaliação do currículo na rede municipal de ensino: um estudo multicaso e propositivo no contexto institucional de escolas do ensino básico de Salvador-Bahia. 2009. Dissertação de Mestrado [Programa de Pós-Graduação em Educação], Universidade Federal da Bahia, 2009.

SANTOS, Kelly Cristina dos. Autonomia da criança: transição da educação infantil para o ensino fundamental, conforme as prescrições oficiais. 2007. Dissertação de Mestrado [Programa de Estudos Pós-Graduados em Educação: História, Política, Sociedade], Pontifícia Universidade Católica de São Paulo, 2007.

SILVA, Neisi Maria da Guia. Diretrizes curriculares do município de Goiânia no contexto de uma política curricular nacional. 2009. Dissertação de Mestrado [Programa de Pós-Graduação em Educação], Universidade Federal de Góias, 2009.

SINHORI, Eliane de Fátima Inglez. A construção do currículo do $1^{\circ}$ ano do ensino fundamental de nove anos na rede municipal de balneário Camboriú. 2011. Dissertação de Mestrado [Programa de Pós-Graduação em Educação], Universidade do Vale do Itajaí, 2011.

SOBRAL, Elaine Luciana da Silva. Proposta curricular para educação infantil: (re)significando saberes docentes. 2008. Dissertação de Mestrado [Programa de Pós-Graduação em Educação], Universidade Federal do Rio Grande do Norte, 2008. 
WIGGERS, Verena. As orientações pedagógicas da educação infantil em municípios de Santa Catarina. 2007. Dissertação de Mestrado [Programa de Estudos Pós-Graduados em Educação: Currículo], Pontifícia Universidade Católica de São Paulo, 2007.

XAVIER, Glaucia de Carmo. O currículo e a educação inclusiva: a prática curricular e suas implicações na inclusão escolar de alunos com necessidades educacionais especiais. 2008. Dissertação de Mestrado [Programa de Pós-Graduação em Educação], Pontificia Universidade Católica de Minas Gerais, 2008.

Texto recebido em 02/08/2019.

Texto aprovado em 07/10/201. 